\title{
Saving Toronto Hydro Telecom's One Zone project from itself: alternative models for urban public wireless infrastructure
}

\author{
Andrew Clement \\ University of Toronto \\ <andrew.clement@utoronto.ca> \\ Amelia Bryne Potter

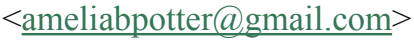

\section{Introduction}

This field note examines the development of a major municipal Wi-Fi service and how its private sector financial and governance model has reduced its potential benefit to the public. It discusses the case of Toronto Hydro Telecom, a publicly owned corporation, and its One Zone Wi-Fi project, which appears to be faltering despite initial optimism and technical success. Currently being considered for sale, if the company is sold a major opportunity will be lost. If the company remains in public hands and pursues a more publicly oriented model, rather than continuing with the commercial competitor approach, it could be using its technologies and public assets to yield much greater financial and social benefits in the long term. Depending on whether the sale proceeds, Toronto Hydro Telecom can serve either as a cautionary or inspirational tale that encourages other municipal governments with similar assets to take an active role in developing civic broadband networks.

\section{The Case of Toronto Hydro Telecom's OneZone}

In 2006 Toronto Hydro Telecom (THT) boldly announced that it would shortly begin rolling out city-wide Wi-Fi bringing affordable, ubiquitous internet access to the 1 million households and 80,000 businesses in Canada's largest city. At that time, THT as a city government-owned private corporation, seemed well positioned to take the lead in providing universal internet connectivity. THT already operated a 450-kilometre fiber-optic network providing data services to many of Toronto's major businesses. With the recent acquisition of the city's street lighting poles by its sister company it could relatively cheaply and easily deploy meshing technologies to blanket the entire $600+$ square $\mathrm{km}$ of metropolitan Toronto. THT launched the first phase in September 2006 with wireless coverage of downtown Toronto (6 km sq). After a 7-month free period which attracted more than 40,000 registered users, in 2007 One Zone now is offered at commercially competitive rates $(\$ 29 /$ month, $\$ 9.99 /$ day, $\$ 4.99 /$ hour).

In important respects, the THT One Zone has been a resounding technical success. For example, Novarum, an independent broadband wireless consulting firm which had recently tested the leading wireless services in North America, announced that One Zone was by far the leader in terms of performance, delivering Internet upload and download rates at 5 Mbps. According to their report, "Most impressive was the fact that this exceptional 
performance is being delivered in the challenging environment of a dense urban canyon." While the number of subscribers has understandably fallen considerably from the free trial period, THT still plans to extend the service to cover the rest of Toronto, if the return on investment (ROI) is favorable.

However, behind this story of apparent success and promise lie several complexities, shortcomings and missed opportunities. These are mainly related to THT's pursuit of a commercial competitor business model, which neglects the many unmet networking needs of Torontonians and inhibits the integration of this initiative with complementary public networking projects. As a private corporation, THT's principal mandate is to make money for its sole shareholder, the City of Toronto, but it gives no indication of pursuing the more socially oriented goals common to municipal projects, such as reducing socio-economic disparities (aka 'closing the digital divide'), improving municipal services, or enabling civic networking applications.

In effect THT is seeking to make a profit from Toronto residents by charging them for access to facilities they already own, such as conduits, fiber cabling and streetlights. Instead of hiding a taxation scheme in this way, THT could more efficiently and directly provide services of benefit to the public-

\section{Vision of a THT Public Interest Network}

Operating on a public utility model, THT could provide, among other things, the basic residential internet service needed by nearly all Toronto citizens. Based on THT's cost figures, if the service were to be offered ubiquitously as originally planned, the average annual household cost would be about $\$ 100$. If this were included in taxes, the $\sim 60 \%$ of households currently subscribing to internet service would save on average $\$ 300-400$ per year. Those households that currently rely on dial-up would save less, but have much better service. Given that connection cost is a major deterrent for those with lower incomes, we can expect that many of the households which currently do not have internet access would get it for the first time. Initial wireless connectivity could be later supplemented by more reliable and higher capacity fiber connections, as THT expands its network.

In addition, a THT citywide fiber/wireless network could be an important boost to City departments and other civic services that have growing needs for networking, such as education, libraries, police and emergency health services, the Ontario Smart Meter program, parking, parks and recreation, and building inspectors. Not only would the city's major institutions, most notably schools, be better served if linked via city-controlled fiber, they could further serve as 'anchor tenants' that would then make connecting residences and businesses in their vicinity much cheaper. Structuring the network with open architectures, where ISPs or businesses with networking needs could purchase bandwidth from THT at wholesale rates, would also help foster competition among commercial providers and stimulate a variety of innovative new services.

\section{The Key Challenge: Governance Model}

Toronto Hydro Telecom faces a number of hurdles in achieving this public benefit vision for its Wi-Fi and fiber networks. These include such common challenges as a lack of access to licensed broadband spectrum; threat of opposition from incumbent telecom providers; and uncertainly about the future of Wi-Fi technologies. Yet, the most significant challenge THT faces in acting in the public interest may be its governance structure. THT's current financial status as a private corporation, formally requiring a profit-over-publicinterest orientation, resulted from provincial re-regulation of the electricity industry in the late 1990's. Legislation passed by the neo-liberal government of the time required cities in 
Ontario to privatize their public electricity distribution enterprises and spin off certain company assets, such as telecommunications, into separate, private corporations, one of which became THT. The perverse result is that while the taxpayers of Toronto still own THT, they are in effect blocked from using it as a means to directly serve their networking needs. At the same time, because of the fetters on its borrowing powers, it is prevented from acting as a fully independent private sector actor.

The tension inherent in this ambiguous status has recently come to a head and Toronto Hydro Telecom is now at a critical juncture. In January 2008 its parent company, apparently in response to a number of purchase bids, announced that it was soliciting expressions of interest from prospective buyers of THT. In March however, under pressure from CUPE Local One, the union representing 27 of THT's workers, Toronto Mayor David Miller asked Toronto Hydro to hold off on the sale, so the city could "consider whether there are other models that work". CUPE Local One has mounted a public campaign to keep THT public, mainly highlighting the wide range of social benefits that would be lost were THT to be sold. It is also pointing out that even in strictly financial terms the estimated $\$ 50 \mathrm{M}$ that would accrue to the city from a sale at this point would sell short its profit potential. (see: http://KeepTelecomPublic.ca) A decision on whether the sale will go ahead is expected by early June 2008.

Toronto Hydro Telecom has the resources and experience to build a broadband network that would serve the public interest, but this opportunity has so far been missed because of political shortsightedness at all levels of government, and THT's consequent focus on a commercial, competitive model. This could change with strong political leadership at the municipal level. The City of Toronto's political will is the best hope in stopping the sale, as well as for achieving a more publicly beneficial Wi-Fi and fiber network for Toronto. Ultimately this likely means directly confronting the provincial legislation that led to THT's legal and ownership structure. But more immediately this will involve working creatively within the current framework, finding ways to instruct THT to operate in the public interest. An important precedent for this is the priority that Toronto Hydro Energy, THT's sister company which distributes electricity in Toronto, places on energy saving measures, which are counter to its short-term financial interests but respond to strong popular and political pressures to promote long-term environmental sustainability. A similar argument can be made for universal, affordable broadband services. It remains to be seen whether the City of Toronto and Toronto Hydro Telecom will step-up to this challenge, but if they do, the citizens of Toronto stand to gain a valuable public infrastructure appropriate to this information age.

\section{Wider Lessons}

While THT One Zone has so far been disappointing, its successes, shortcomings, and opportunities provide some useful lessons for other city governments. Broadband has become a crucial infrastructure for a wide range of everyday services and transactions, as well as for communication and economic, political, and social participation. As such, the availability of affordable, high quality broadband is increasingly important. While federal and regional governments can, and should, play a role in promoting broadband infrastructure, local governments are often well positioned to address community broadband needs.

As providers of other basic infrastructure services, local governments have experience managing large-scale projects. They are also well suited for guiding infrastructure creation best developed and maintained over the long-term. Local governments may play a fundamental role in helping communities to build-out fiber-optic networks, which require significant investments. Fiber may first be laid to serve particular 
kinds of users, such as schools and hospitals, and later extended to businesses, and, finally to homes. While fiber networks are in development Wi-Fi can help extend connectively to those locations not yet served by fiber. The technological possibilities are at hand. What is needed is for local governments to deploy their assets creatively and assertively - by putting public interest ahead of short-term profit-seeking. Depending on the outcome of current struggles around the future status and direction of Toronto Hydro Telecom, it may serve as a cautionary tale of missed opportunity, or an inspiration for other municipalities seeking to serve their citizens' telecommunications needs. Stay tuned.

This field note draws on Clement, A. \& Potter, A. B. (2008) Internet Infrastructure for All: Time for Canadian Municipalities to Step Up! in Moll, M. \& Shade, L. R. For Sale to the Highest Bidder: Telecom Policy in Canada (pp. 109-119). Ottawa: Canadian Centre for Policy Alternatives (CCPA). A version of this paper with extensive endnotes can be found in the Community Wireless Infrastructure Research Project (CWIRP.ca) Publications collection of the University of Toronto's Research Repository at: http://hdl.handle.net/1807/10240 